\title{
Weitere Studien über die normale Verdauung der Eiweißkörper im Magendarmkanal des Hundes.
}

\author{
V. Mitteilung. \\ Von
}

Emil Abderhalden, E. S. London (St. Petersburg) und E. B. Reemlin (Cincinnati).

(Aus dem physiologischen Institute der tierärztlichen Hochschule, Berlin, und dem pathologischen Laboratorium des Kaiserl. Institutes für experimentelle Medizin, St. Petersburg.)

(Der Redaktion zugegangen am 27. Dezember 1908.)

Die folgende Untersuchung bildet eine Fortsetzung der Arbeit des einen von uns mit E. S. London und Berthold Oppler. ${ }^{1}$ ) Es galt, festzustellen, ob im Magendarmkanal der Abbau verschiedenartiger Proteine ebenfalls stufenweise in der Art vor sich geht, daß die einzelnen Aminosäuren verschieden rasch abgespalten werden. Die Entscheidung dieser Frage erscheint uns als Beitrag zum Probleme des Umfanges der Hydrolyse der Proteine unter der Einwirkung der Fermente des Magendarmkanales von großer Bedeutung. Bei der früheren Untersuchung ist der Nachweis erbracht worden, daß Gliadin im Magendarmkanal in ganz analoger Weise zum Abbau gelangt, wie im Reagenzglas. In den tiefer gelegenen Darmteilen (Ileum) lassen sich «Peptone» nachweisen, die keine Spur von Tyrosin mehr enthalten, dagegen noch reichlich Glutaminsäure und andere Aminosäuren. Auch bei gemischter Casein- und Fleischfütterung wurde das gleiche Resultat erhalten. Wir haben diese Versuche auf Edestin ausgedehnt. Das verfütterte Edestin war aus Baumwollsamen gewonnen worden. Auch hier wurden

1) Emil Abderhalden, E. S. London und Berthold Oppler, Weitere Studien über die normale Verdauung der Eiweißkörper im Magendarmkanal des Hundes. VI. Mitteilung. Diese Zeitschrift, Bd. LV, S. 447, 1908. 
Hunde verwendet, die an verschiedenen Teilen des Magendarmtractus Fisteln besaßen. Die Technik der Untersuchung war dieselbe, wie sie in der erwähnten Arbeit geschildert worden ist. Wir begnügen uns deshalb mit der Mitteilung der Resultate.

1. Duodenumfistel. (Hund Cygan II.) Zur Untersuchung wurden $145 \mathrm{~g}$ des aufgefangenen, getockneten Chymus verwendet. Mit Phosphorwolframsäure fielen aus einer 1\% igen wässerigen Lösung $63 \mathrm{~g}$. Im Filtrat der Fällung verblieben $68 \mathrm{~g}$.

Beide Substanzen wurden durch 16 stündiges Kochen mit $25 \%$ iger Schwefelsäure vollständig hydrolysiert. Nunmehr wurde nach Entfernung der Schwefelsäure mit Baryt das Tyrosin abgeschieden und in der Mutterlauge dieser Aminosäure die Glutaminsäure quantitativ als salzsaures Salz bestimmt.

Im nicht fällbaren Teil waren vorhanden $1,5 \mathrm{~g}$ Tyrosin und 2,5 g Glutaminsäure.

Aus dem fällbaren Teil erhielten wir $0,80 \mathrm{~g}$ Tyrosin und 10,5 g Glutaminsäure.

2. Duodenumfistel. (Ljoschke-Cygan.) Angewandt wurden $180 \mathrm{~g}$ des eingetrockneten Chymus. Mit Phosphorwolframsäure waren fällbar $85 \mathrm{~g}$, nicht fällbar $85 \mathrm{~g}$.

Im nicht fällbaren Teil waren vorhanden $2,8 \mathrm{~g}$ Tyrosin und $5,5 \mathrm{~g}$ Glutaminsäure.

Aus dem fällbaren Teil gewannen wir 0,75 g Tyrosin und 14,5 g Glutaminsäure.

3. Jejunumfistel. (Hund Rishik.) Verwendet wurden $80 \mathrm{~g}$ des Chymus. Davon erhielten wir nach der Fällung mit Phosphorwolframsäure aus einer 1\% igen wässerigen Lösung aus dem Niederschlage $30 \mathrm{~g}$ wieder und aus dem Filtrate $40 \mathrm{~g}$.

Der nicht fällbare Teil enthielt an Tyrosin $2,5 \mathrm{~g}$ und an Glutaminsäure $4,5 \mathrm{~g}$.

Aus dem fällbaren Teil isolierten wir an Tyrosin $0,25 \mathrm{~g}$ und an Glutaminsäure $8,5 \mathrm{~g}$.

4. Ileumfistel. (Hund Zolty.) Angewandt $120 \mathrm{~g}$. Mit Phosphorwolframsäure fällbar $35 \mathrm{~g}$, nicht fällbar $70 \mathrm{~g}$.

Der nicht fällbare Anteil enthielt 1,0 $\mathrm{g}$ Tyrosin und 3,5 $\mathrm{g}$ Glutaminsäure.

Der fällbare Teil ergab $0 \mathrm{~g}$ Tyrosin und 8,0 g Glutaminsäure. 
434 Abderhalden, London und Reemlin, Über Eiweißkörper.: V.

Aus dieser Übersicht ergibt sich ohne weiteres, daß die Menge der mit Phosphorwolframsäure fällbaren Produkte beständig abnimmt, aus je tieferen Darmpartien der untersuchte Chymus stammt. Ferner ergibt sich, daß in dem mit Phosphorwolframsäure nicht fällbaren Anteil der Gehalt an Tyrosin bereits im Duodenum ein sehr hoher ist, während in den mit Phosphorwolframsäure fallenden Produkten der Tyrosingehalt ein sehr geringer und im Inhalt des Ileums $=0$ ist. Es zeigt diese Beobachtung, daß das Tyrosin sehr bald abgespalten wird. Es muß allerdings hervorgehoben werden, daß wir bei diesen Untersuchungen den mit Phosphorwolframsäure nicht fällbaren Teil der totalen Hydrolyse unterworfen haben und auf diese Weise eventuell eine Abspaltung von Tyrosin aus einfacheren «Peptonen* stattgefunden haben könnte. Wir haben uns jedoch durch direkte Versuche überzeugt, daß ganz gleiche Tyrosinwerte erhalten wurden, wenn die wässerige Lösung des mit Phosphorwolframsäure nicht fällbaren Teils einfach eingeengt wurde. Die Glutaminsäure wird nicht so rasch abgespalten. Es findet sich selbst im lleum ein noch recht erheblicher Teil dieser Aminosäure in komplizierteren, mit Phosphorwolframsäure fällbaren Produkten vor. 